\title{
Implantation of Neural Probes in the Brain Elicits Oxidative Stress
}

\begin{abstract}
Evon S. Ereifej ${ }^{1,2 *}$, Griffin M. Rial ${ }^{1,2}$, John K. Hermann ${ }^{1,2}$, Cara S. Smith ${ }^{1,2}$, Seth M. Meade ${ }^{1,2}$, Jacob M. Rayyan ${ }^{1,2}$, Keying Chen ${ }^{1,2}$, He Feng ${ }^{1,2}$ and Jeffrey R. Capadona ${ }^{1,2 *}$
\end{abstract}

${ }^{1}$ Department of Biomedical Engineering, Case Western Reserve University, Cleveland, $\mathrm{OH}$, United States, ${ }^{2}$ Advanced Platform Technology Center, Louis Stokes Cleveland Department of Veterans Affairs Medical Center, Cleveland, OH, United States

Clinical implantation of intracortical microelectrodes has been hindered, at least in part, by the perpetual inflammatory response occurring after device implantation. The neuroinflammatory response observed after device implantation has been correlated to oxidative stress that occurs due to neurological injury and disease. However, there has yet to be a definitive link of oxidative stress to intracortical microelectrode implantation.

OPEN ACCESS

Edited by:

Paul De Vos,

University Medical Center Groningen, Netherlands

Reviewed by: Rajendra K. Singh, Dankook University,

South Korea

Banani Kundu,

3B's Research Group, Portugal

*Correspondence:

Evon S. Ereife

eereifej@aptcenter.org;

Jeffrey R. Capadona

jrc35@case.edu

Specialty section:

This article was submitted to Biomaterials,

a section of the journal Frontiers in Bioengineering and Biotechnology

Received: 31 October 2017 Accepted: 22 January 2018 Published: 12 February 2018

Citation: Ereifej ES, Rial GM, Hermann JK, Smith CS, Meade SM, Rayyan JM, Chen K, Feng H and Capadona JR (2018) Implantation of Neural Probes in the Brain Elicits Oxidative Stress.

Front. Bioeng. Biotechnol. 6:9. doi: 10.3389/fbioe.2018.00009
Thus, the objective of this study is to give direct evidence of oxidative stress following intracortical microelectrode implantation. This study also aims to identify potential molecular targets to attenuate oxidative stress observed postimplantation. Here, we implanted adult rats with silicon non-functional microelectrode probes for 4 weeks and compared the oxidative stress response to no surgery controls through postmortem gene expression analysis and qualitative histological observation of oxidative stress markers. Gene expression analysis results at 4 weeks postimplantation indicated that EH domain-containing 2, prion protein gene (Prnp), and Stearoyl-Coenzyme A desaturase 1 (Scd1) were all significantly higher for animals implanted with intracortical microelectrode probes compared to no surgery control animals. To the contrary, NADPH oxidase activator 1 (Noxa1) relative gene expression was significantly lower for implanted animals compared to no surgery control animals. Histological observation of oxidative stress showed an increased expression of oxidized proteins, lipids, and nucleic acids concentrated around the implant site. Collectively, our results reveal there is a presence of oxidative stress following intracortical microelectrode implantation compared to no surgery controls. Further investigation targeting these specific oxidative stress linked genes could be beneficial to understanding potential mechanisms and downstream therapeutics that can be utilized to reduce oxidative stress-mediated damage following microelectrode implantation.

Keywords: oxidative stress, intracortical microelectrodes, gene expression, histology, brain

\section{INTRODUCTION}

Intracortical microelectrodes were initially designed as a neuroscience tool to allow researchers the ability to investigate and understand how the nervous system works (Renshaw et al., 1940; Grundfest and Campbell, 1942; Grundfest et al., 1950). In addition to their role as a research tool, intracortical microelectrodes have the ability to treat patients with a wide range of neurological injuries and 
degenerative diseases, either directly through clinical implantation or indirectly by giving researchers a tool to better understand these diseases. For example, intracortical microelectrodes were used recently to allow patients with amyotrophic lateral sclerosis (ALS) to use their thoughts to control virtual neural cursors on the computer screen (Gilja et al., 2015). Over the past two decades, brain computer interfaces involving intracortical microelectrodes have entered clinical trials for patients with motor deficits, such as spinal cord injuries and ALS (Gilja et al., 2015; Schroeder and Chestek, 2016; Ajiboye et al., 2017). Unfortunately, recording quality of microelectrodes decreases within weeks and diminishes within a few years due to the complex inflammatory response observed after electrode implantation (Chestek et al., 2011; Jorfi et al., 2014; Kozai et al., 2015).

The initial insertion of intracortical microelectrodes results in an injury of the brain tissue, eliciting a chain reaction of chemical and biological events that contributes to the ultimate failure of the device to record action potentials for local neurons (Polikov et al., 2005; Potter et al., 2012a; Kozai et al., 2015). One mechanism that has been suggested to play a key role in the failure of microelectrodes is oxidative stress at the microelectrode-tissue interface (McConnell, 2008; Saxena et al., 2013; Potter et al., 2014; PotterBaker and Capadona, 2015; Potter-Baker et al., 2015; Nguyen et al., 2016). Specifically, the presence of oxidative stress can (1) directly facilitate neuronal cell death (2) perpetuate the foreign body response to the implanted device, and (3) facilitate corrosion and delamination of the microelectrode surface (Prasad et al., 2012, 2014; Potter et al., 2013; Takmakov et al., 2015). Figure 1 illustrates the potential consequences from oxidative stress that can occur following the implantation of neural probes in the brain.

The breaching of the blood-brain barrier results in an infiltration of neurotoxicfactors and pro-inflammatory cells which lead to neuronal degeneration and death (Potter et al., 2013; Saxena et al., 2013). Pro-inflammatory cells (activated microglia, macrophages, and astrocytes) remain around the implant site for the duration of implantation (McConnell et al., 2009; Ravikumar et al., 2014; Nguyen et al., 2016). Furthermore, it is understood that these proinflammatory cells release free radicals, reactive oxygen species (ROS), and reactive nitrogen species when activated (Streit et al., 1999; Abbott et al., 2006; Kettenmann et al., 2011). The release of reactive species and radicals around implanted intracortical microelectrodes can lead to oxidation of the electrode surface, and as a result, the corrosive breakdown of the material (Schmitt et al., 1999; Takmakov et al., 2015). For example, Prasad et al. (2014) demonstrated the accumulation of ferritin, indicative of perpetuating oxidative stress, around implanted functional microelectrodes 10 weeks after implantation, and suggested a correlation to the corrosion of both insulating and conductive microelectrode material components. McConnell et al. (2009) reported that implantation of microelectrodes could result in the accumulation of hemosiderin-laden macrophages, indicating that the implant site was hemorrhagic and speculated to be a byproduct of oxidative stress, as early as 2 weeks and up to 16 weeks post-microelectrode implantation. Additionally, Takmakov et al. (2015) showed that ROS, released in their reactive accelerated aging (RAA) in vitro system, created structural damage to microelectrode arrays thereby altering the electrical properties via decreased electrode impedance. The decline in impedance in their in vitro RAA system, which simulated 6 months in vivo, was reported to be consistent with published reports on in vivo impedance changes (Takmakov et al., 2015).

The brain is highly susceptible to oxidative stress due to its biochemical composition, specifically unsaturated lipids, which are targeted for oxidative modification and lipid peroxidation (Gallego et al., 2011). Furthermore, due to the brain's high oxygen requirement ( $20 \%$ of the total oxygen intake is used), it has an increased risk of peroxidation (Gallego et al., 2011). Specifically, neurons are the most vulnerable cell to oxidative damage, due to their high content of methyl ions and low antioxidant activity (Floyd and Carney, 1992; Gallego et al., 2011). When subjected to a continuous state of oxidative stress, neurons result in severe damage to their cellular constituents including proteins, DNA, and lipids (Dawson and Dawson, 1996; Gallego et al., 2011). The pathology and molecular biomarkers for diseases such as Alzheimer's and Parkinson's disease include neurodegeneration and neuronal cell death, which have been linked to the abnormal cellular proteins and lipids formed due to ROS accumulation (Smith et al., 2000; Emerit et al., 2004; Lin and Beal, 2006; Gallego et al., 2011). Notably, our lab has shown the use of antioxidants, either locally or systemically, results in higher densities of neuronal nuclei and more viable neurons at the intracortical microelectrode/tissue interface (Potter et al., 2013, 2014; Jorfi et al., 2014; Potter-Baker et al., 2014; Nguyen et al., 2016).

The above literature review established that there have been many studies which suggest oxidative stress as a key component of the failure mechanism of intracortical microelectrodes. However, a definitive link has yet to be determined. Given the potential role oxidative stress events play in the failure of intracortical microelectrodes, it is crucial to elucidate and identify the specific cellular and molecular oxidative stress factors involved after intracortical microelectrode implantation. While most previous studies, including our own lab, have focused on the histological analysis of neuroinflammation, the use of gene expression has been shown to be more sensitive than histological analysis-providing more insight into the phenotype of the cells (Karumbaiah et al., 2013; Ereifej et al., 2017). Information with respect to inflammatory and non-inflammatory cell phenotype may more directly facilitate intervention strategies that are clinically translatable if intervention strategies are more specific, minimizing unintentional side effects of broader spectrum therapeutics. Thus, the goal of this study is to give direct evidence of oxidative stress following intracortical microelectrode implantation using gene expression analysis and histological approaches. Prior to this study, we hypothesized that there is an increased presence of oxidative stress markers following intracortical microelectrode probe implantation. To evaluate our hypothesis, we implanted adult rats with silicon non-functional microelectrode probes for four weeks and compared the oxidative stress response to no surgery sham controls. To assess the cellular and molecular oxidative stress response to intracortical microelectrode implantation, we quantified oxidative stress markers through postmortem gene expression analysis and qualitatively observed the presence of 


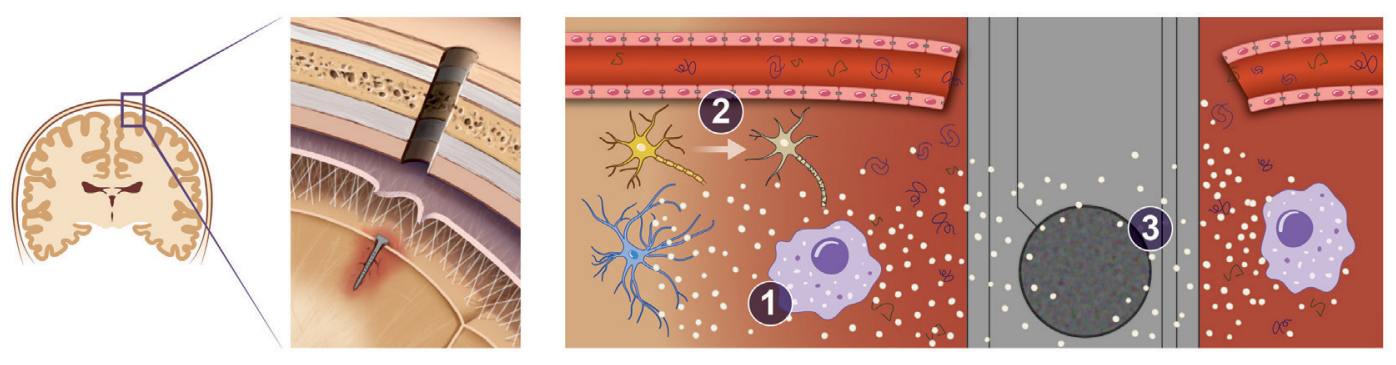

Potential Consequences of Oxidative Stress following Implantation of Neural Probes in the Brain

Microglia and
Macrophages $\quad \begin{aligned} & \begin{array}{l}\text { ROS perpetuate the foreign body response to the implanted device: } \\ \text { Oxidative stress further increases ROS production, consequently damaging } \\ \text { the mitochondria, creating a cycle that perpetuates the effects of ROS. } \\ \text { - Ultimately activating the NF-KB signaling pathway. }\end{array} \\ & \text { NOStrocytes }\end{aligned}$

Illustration courtesy of Cleveland FES Center

FIGURE 1 | Oxidative stress following neural probe implantation. The implantation of neural probes leads to the overproduction of reactive oxygen species (ROS) which can consequently (1) perpetuate the foreign body response, (2) facilitate neuronal death, and (3) facilitate corrosion and delamination of the microelectrode surface.

oxidative stress markers surrounding the implant though histological staining.

\section{MATERIALS AND METHODS}

\section{Neural Probe Implantation Procedure}

All animal procedures were approved by the Institutional Animal Care and Use Committee at the Louis Stokes Cleveland Department of Veterans Affairs Medical Center. A total of eight adult (8-10 weeks old, 225 g) male Sprague Dawley rats were used in this study. Four of the rats were implanted with neural probes in the sensory cortex while the other four were used as no surgery sham controls. Genomic analysis was performed on the same animals used for histological analysis in this study. Similar to previous surgical procedures published by this lab, each animal was anesthetized to the surgical plane in an isoflurane chamber (3.5\% in $1.5 \mathrm{~L} / \mathrm{min}_{2}$ ) for $4 \mathrm{~min}$ (Ereifej et al., 2017; Goss-Varley et al., 2017). Following which, isoflurane was administered through a nose cone at $2.5 \%$ in order to shave the incision site and deliver a subcutaneous injection of Marcaine. Subcutaneous Carprofen $(5 \mathrm{mg} / \mathrm{kg})$ and Cefazolin $(25 \mathrm{mg} / \mathrm{kg})$ injections were given for analgesia and antibiotics, respectively. The rat was then mounted to a stereotaxic frame connected to a nose cone flowing
$1-2.5 \%$ isoflurane to maintain anesthesia throughout the surgery. Seven alternating cotton tipped applicators of chlorhexidine gluconate and isopropanol were used to sterilize the surgical site. Body temperature was maintained via a circulating water pad and vitals (body temperature, heart and respiratory rate, and oxygen levels) were monitored using a heart rate and blood-oxygen measurement system (MouseSTAT ${ }^{\circledR}$ Pulse Oximeter \& Heart Rate Monitor, Kent Scientific Corp., Torrington, CT, USA).

The surgery began with an incision down the midline of the head and retraction of the skin to view the skull. The periosteum was cleaned off of the skull with a cotton swab applicator, followed by dehydration of the skull using hydrogen peroxide, and application of Vetbond, an animal tissue adhesive, to prime the skull. A sterile ruler and forceps were used to mark the area to be drilled, $2 \mathrm{~mm}$ lateral to midline, $3 \mathrm{~mm}$ posterior to bregma (sensory cortex). The dura was carefully reflected using a $45^{\circ}$ angle dura pick to expose the brain. The implant was inserted manually using forceps. The surgery site was covered with an insulating silicone elastomer, Kwik-Cast (World Precision Instruments, Sarasota, FL), followed by Fusio and Flow-it ALC (Pentron Clinical, Wallingford, CT) UV-cured dental cement to build a stable headcap covering the entire implant. The skin was sutured shut with 5-0 monofilament polypropylene suture (Henry Schein, Melville, NY, USA), and antibiotic ointment was applied 
to the suture path. Analgesia and antibiotics were administered for 3 days postoperatively.

\section{Tissue Processing}

Animals were anesthetized by intraperitoneal injections of ketamine $(160 \mathrm{mg} / \mathrm{kg})$ and xylazine $(20 \mathrm{mg} / \mathrm{kg})$ at 4 weeks postimplantation, as a predetermined end point. Animals were perfused with $1 \times$ phosphate buffer saline (PBS, Invitrogen, Carlsbad, CA, USA) to clear the blood, followed by $30 \%$ sucrose (Sigma, St. Louis, MO, USA) in $1 \times$ PBS to cryoprotect the tissue. The brain was removed carefully from the skull and the electrode was explanted. The brain was then frozen in optimal cutting temperature compound (OCT, Tissue Tek, Torrance, CA, USA) on dry ice and stored at $-80^{\circ} \mathrm{C}$ for cryosectioning.

The cryostat, blades, and slides were decontaminated of RNase enzymes using RNaseZap ${ }^{\circledR}$ (Thermo Fisher Scientific, Waltham, MA, USA). Brains were sliced transversely at $20 \mu \mathrm{m}$ thick slices and mounted onto either glass slides for staining or Leica FrameSlides PEN-Membrane $4.0 \mu \mathrm{m}$ (Leica, Wetzlar, Germany) slides for Laser Capture Microdissection and downstream genetic analysis. Slides were then stored at $-80^{\circ} \mathrm{C}$ until LCM or immunohistochemical labeling.

\section{Laser Capture Microdissection}

To prepare for $\mathrm{LCM}$, the slides were removed from $-80^{\circ} \mathrm{C}$ storage and immediately submerged in the following ethanol series: $95 \%$ (30 s), 70\% (30 s), and 50\% (30 s). There were 18 tissue slices per animal used for LCM tissue collection. The tissue was stained with Cresyl Violet (in 50\% ethanol), followed by a dehydration series according to the manufacturer's protocol (AM1935, Ambion, Waltham, MA, USA). Following the dehydration, the tissue was immersed in xylene for $5 \mathrm{~min}$ and then air-dried for $5 \mathrm{~min}$. Slides were transferred to an RNase contamination-free Leica LMD7000 microdissection system. The LCM microscope and Leica software was used to identify the implant sites in the surgery tissue, and the respective location in the sham tissue based on Cresyl Violet staining. A $500 \mu \mathrm{m}$ radius circle was centered on the site of the implant (or sham site), and the tissue was laser cut. The cut tissue pieces were immediately collected in $500 \mu \mathrm{L}$ tubes containing Qiazol (Qiagen, Valencia, CA, USA), an RNA extraction lysis buffer. Throughout the process, the microdissected tissue samples were preserved on ice. RNA was extracted and purified the same day as collection and stored at $-80^{\circ} \mathrm{C}$ for further processing.

\section{Real-time Polymerase Chain Reaction}

RNA was purified using RNeasy Micro Kit (Qiagen, Valencia, CA, USA) in accordance with the manufacturer's protocol. The purity and concentration of the RNA was measured using a NanoDrop apparatus measuring the ratio between the 260 and $280 \mathrm{~nm}$ wavelengths (Thermo Fisher Scientific, Waltham, MA, USA). Reverse transcriptase converted the mRNA to a cDNA template using random primers and a thermal cycle (GeneAmp PCR System 9700, Applied Biosystems, Foster City, CA, USA) following the manufacturer's protocol (Qiagen RT2 Profiler, Qiagen, Valencia, CA, USA). PCR analysis was conducted using cDNA equivalent to $40 \mathrm{ng}$ of total RNA used. Oxidative Stress RT $^{2}$ Profiler PCR Arrays (330231; Qiagen, Valencia, CA, USA) containing 84 genes involved in the oxidative stress pathway were utilized. The PCR Arrays contained positive PCR controls, reverse transcriptase controls, genomic DNA contamination controls as well as five endogenous controls, actin beta, beta-2 microglobulin (B2M), hypoxanthine phosphoribosyl transferase 1, lactate dehydrogenase A, and ribosomal protein. For our analysis, the B2M was utilized as the endogenous control. SYBR green (Qiagen, Valencia, CA, USA) was used as the fluorescence tag. cDNA templates along with the master mix were read in a 96-well optical plate. The instrument used for the measurement was a 7900HT Real-Time PCR system (Applied Biosystems) running the following protocol: (1) hold $95^{\circ} \mathrm{C}$ for $10 \mathrm{~min}$ and (2) $40 \mathrm{cycles}$ at $95^{\circ} \mathrm{C}$ for $15 \mathrm{~s}$ and $60^{\circ} \mathrm{C}$ for $1 \mathrm{~min}$. Melt curves for each gene were ran and evaluated to verify proper runs running the following: (1) hold $95^{\circ} \mathrm{C}$ for $15 \mathrm{~s}$, (2) hold $60^{\circ} \mathrm{C}$ for $15 \mathrm{~s}$, and (3) hold $95^{\circ} \mathrm{C}$ for $15 \mathrm{~s}$. Using the SDS 2.3 software (Applied Biosystems, Foster City, CA, USA) the threshold cycle (Ct) values for each sample and primer pair were calculate. The delta $(\Delta)$ Ct method was utilized to calculate the relative gene expression fold change (R) (Livak and Schmittgen, 2001; Schmittgen and Livak, 2008).

The following equations were used:

$$
\Delta \mathrm{Ct}=\mathrm{Ct}(\text { Gene of Interest })-\mathrm{Ct}(\mathrm{B} 2 \mathrm{M})
$$

$$
R=2^{\Delta \mathrm{Ct}}
$$

\section{Histology}

In order to determine the relationship between neural probe implantation and oxidative stress, immunohistochemistry (IHC) of the peroxidase-anti-peroxidase staining method was used with 3'-3'-diaminobenzidine (DAB; Dako) as a chromogen. Staining was employed to analyze the presence of oxidized nucleic acids (8-hydroxydeoxyguanosine), lipids (hydroxynonenal), and proteins [nitrotyrosine (NT)]. In addition to colorimetric DAB staining, adjacent tissue slices were fluorescently stained for glial fibrillary acidic protein (GFAP) to accurately define the region of implantation by identifying the location of the glial scar surrounding the implant (Potter et al., 2012a). Histology controls for colorimetric DAB staining were no surgery sham controls.

To prepare tissue for IHC staining, previously established protocols were followed (Potter et al., 2013; Nguyen et al., 2014; Ereifej et al., 2017). Briefly, tissue was first equilibrated to room temperature (RT) in a humidity chamber. OCT was removed with three consecutive PBS washes. Each wash consisted of a gentle application of PBS to tissue followed by a 5-min incubation prior to beginning the next wash. Following OCT removal, tissue was fixed with $4 \%$ formaldehyde for $10 \mathrm{~min}$ at RT.

\section{Fluorescent Staining}

Following fixation, tissue was rinsed, rehydrated, and permeabilized with PBS containing $0.1 \%$ Triton-X (PBS-T). Tissue was then blocked for $1 \mathrm{~h}$ with goat serum blocking buffer [4\% v/v serum (Invitrogen, Carlsbad, CA, USA), 0.3\% v/v Triton-X 100, $0.1 \% \mathrm{w} / \mathrm{v}$ sodium azide (Sigma)]. Next, astrocytic scarring was detected via rabbit anti-GFAP (1:500, Dako) for astrocytes. Primary antibodies were incubated for $18 \mathrm{~h}$ at $4^{\circ} \mathrm{C}$. Following primary antibody incubation, tissue was washed six times for 
5 min each with PBS-T. Next, AlexaFlour conjugated antibodies $(1: 1,000)$ were incubated for $2 \mathrm{~h}$ at RT. DAPI $\left(4^{\prime}, 6\right.$-diamidino2-phenylindole) was included in this incubation to counterstain all cell nuclei. Following incubation, tissue was again washed six times for 5 min each with PBS-T, followed with a 10 min $0.5 \mathrm{mM}$ copper sulfate solution (50 mM Ammonium Acetate, $\mathrm{pH} 5.0$; Sigma) to reduce tissue autofluorescence (Potter et al., 2012b). Samples were finally rinsed with deionized water and mounted with Fluoromount-G (Southern Biotech).

\section{Colorimetric Staining}

For oxidative stress immunostaining, previously published protocols were followed (Lee et al., 2012). Following fixation (described above), tissue samples were incubated with $3 \%$ hydrogen peroxide in methanol for $30 \mathrm{~min}$, to quench inherent peroxidase activity. Next, tissue was rinsed and rehydrated with Tris buffered saline ( $50 \mathrm{mM}$ Tris, $150 \mathrm{mM} \mathrm{NaCl}, \mathrm{pH}=7.6$, TBS) for 10 min. Following which, tissue was blocked with $10 \%$ normal goat serum (NGS, Abcam) in TBS for $30 \mathrm{~min}$ and rinsed several times with $1 \%$ NGS in TBS. After blocking and rinsing, primary antibodies diluted in $1 \%$ NGS were added to the slides. Tissue slices were incubated with antibodies for $2 \mathrm{~h}$ at $37^{\circ} \mathrm{C}$ in a humidity chamber. Antibodies and their corresponding concentrations are listed in Table 1. Following tissue incubation with primary antibodies, tissue was rinsed with $1 \%$ NGS, blocked for 10 min with $10 \%$ NGS, and rinsed again with $1 \%$ NGS. Following this rinse, tissue was incubated with species-specific secondary antibodies (EMD Millipore, Burlington, MA, USA) at RT for $30 \mathrm{~min}$. After incubation with secondary antibodies, tissue was again rinsed several times with $1 \%$ NGS in TBS. Next, tissue was incubated with species-specific peroxidase anti-peroxidase (Immunogen) complex at RT for $1 \mathrm{~h}$. Slides were then rinsed with Tris buffer and developed for approximately $5 \mathrm{~min}$ with the chomogen DAB (Dako, Santa Clara, CA, USA). Prior to mounting, slides were incubated for $10 \mathrm{~min}$ each in the following solutions in succession: $70 \%$ ethanol, 95\% ethanol, $100 \%$ ethanol, and Xylene II. Coverslips were then used to mount the slides using permount. Slides were dried overnight on a warm hot plate at $\sim 30^{\circ} \mathrm{C}$.

\section{Imaging}

All slides were imaged under $10 \times$ magnification using a Carl Zeiss AxioObserver Z1 (Zeiss, Inc.) Fluorescently labeled tissue was imaged utilizing an AxioCam MRm monochrome camera (Zeiss, Inc.). DAB labeled tissue was imaged using an AxioCam ERc5 color camera (Zeiss, Inc.). In order to capture the entire area of implantation, the Mosaix module was used to stitch together a $4 \times 4$ tile image. Images shown have been enhanced to improve visual representation.

\section{Statistical Analysis}

For statistical analysis of gene expression, $t$-tests in Minitab 16 (Minitab Inc., State College, PA, USA) were performed. All the RNA from one animal was pooled and analyzed as an independent sample. Significance was defined as $p<0.05$.

Sample size analysis was based upon data observed for Ercc6, Ptgs2 (Cox2), Sod3, and Srxn1 relative gene expression. A power analysis using a two-tailed $t$-test was used to determine the number of animals required to determine statistical significance with a $95 \%$ confidence and power of 0.80 . Pooled standard deviation of 6.35 for Ercc6, 7.42 for Ptgs2 (Cox2), 7.00 for Sod3, and 5.10 for Srxn 1 relative gene expression, and a difference of means between no surgery control and surgery groups of 9.70 for Ercc6, 10.45 for Ptgs2 (Cox2), 10.03 for Sod3, and 8.52 for Srxn1 relative gene expression were assumed.

\section{RESULTS}

\section{Oxidative Stress Gene Expression after Electrode Implantation}

Gene expression analysis was performed on both implanted and no surgery control animals in order to better understand the molecular markers involved in the oxidative stress pathway occurring after intracortical microelectrode implantation. The use of gene expression has been shown to be more sensitive than histological analysis, while also providing more insight into the phenotype of the cells (Karumbaiah et al., 2013; Ereifej et al., 2017). Therefore, RT-PCR arrays for oxidative stress containing 84 distinct genes of interest involved in oxidative stress pathways were utilized for this study. The array was comprised of antioxidant genes, genes involved in the metabolism of ROS, and oxygen transporters. Of the 84 genes analyzed in the array, there were four genes that revealed statistically significant differences between the surgery and sham animals (Table 2): EH domain-containing 2 (Ehd2), prion protein gene (Prnp), Stearoyl-Coenzyme A desaturase 1 (Scd1), and Nicotinamide adenine dinucleotide phosphate oxidase activator 1 (Noxa1). Specifically, at 4 weeks postimplantation, Ehd2, Prnp, and Scd1 relative gene expression were all significantly higher $(p<0.05)$ from animals implanted with intracortical microelectrode probes compared to no surgery control animals (Figures 2A-C). To the contrary, Noxa1 relative gene expression was significantly lower $(p<0.05)$ from implanted animals compared to no surgery control animals (Figure 2D). Ehd2 gene encodes for the EH domain proteins, found on the plasma membrane, which function in both endocytosis and signal transduction pathways (Pohl et al., 2000). Prnp encodes for the membrane protein, cellular prion protein, a glycosylphosphatidylinositol anchored glycoprotein, which is highly expressed in the brain (Ding et al., 2013). Misfolding of

TABLE 1 | Histological markers for oxidative stress.

\begin{tabular}{|c|c|c|c|c|}
\hline Primary antibody & Oxidative stress marker & Supplier & Species & Dilution \\
\hline Anti-nitrotyrosine & Oxidized proteins & Cayman Chemical [10189540] & Rabbit & $1: 500$ \\
\hline Anti-8-hydroxydeoxyguanosine & Oxidized nucleic acids & Abcam (15A3) [ab62623] & Mouse & $1: 500$ \\
\hline Anti-hydroxynonenal & Oxidized lipids & Alpha Diagnostics [HNE11-S] & Rabbit & $1: 3,000$ \\
\hline
\end{tabular}


TABLE 2 | Oxidative stress relative gene expression.

Gene name

Control mean Control SOM Implant mean Implant SOM p-Value

Reactive oxygen species (ROS) metabolism - oxidative stress responsive genes

Amyotrophic lateral sclerosis 2 (juvenile) homolog (human)

Apolipoprotein E

Chemokine (C-C motif) ligand 5

24-dehydrocholesterol reductase

Dual oxidase 2

Excision repair cross-complementing rodent repair deficiency, complementation group 2

Excision repair cross-complementation group 6

Ferritin, heavy polypeptide 1

Glutamate cysteine ligase, catalytic subunit

Glutamate cysteine ligase, modifier subunit

Heme oxygenase (decycling) 1

Heat shock $70 \mathrm{kD}$ protein $1 \mathrm{~A}$

Isocitrate dehydrogenase 1 (NADP+), soluble

Keratin 1

$\mathrm{NAD}(\mathrm{P}) \mathrm{H}$ dehydrogenase, quinone 1

Nudix (nucleoside diphosphate linked moiety $X$ )-type motif 1

Parkinson disease (autosomal recessive, early onset) 7

Prion protein

Proteasome (prosome, macropain) subunit, beta type 5

Selenoprotein P, plasma, 1

Sequestosome 1

Thyroid peroxidase

Thioredoxin 1

Thioredoxin interacting protein

Uncoupling protein 3 (mitochondrial, proton carrier)

ROS metabolism - superoxide dismutases (SOD)

Albumin

Glutathione reductase

Superoxide dismutase 1, soluble

Superoxide dismutase 2, mitochondrial

Superoxide dismutase 3, extracellular

Sulfiredoxin 1 homolog (S. cerevisiae)

Thioredoxin reductase 1

Thioredoxin reductase 2

ROS metabolism - other superoxide metabolism genes

Copper chaperone for superoxide dismutase

Cytochrome b-245, alpha polypeptide

Neutrophil cytosolic factor 1

Neutrophil cytosolic factor 2

Nitric oxide synthase 2, inducible

NADPH oxidase 4

NADPH oxidase activator 1

NADPH oxidase organizer 1

Stearoyl-Coenzyme A desaturase 1

Uncoupling protein 2 (mitochondrial, proton carrier)

ROS metabolism - other ROS Metabolism Genes

Aldehyde oxidase 1

Flavin containing monooxygenase 2

Antioxidants-peroxiredoxins (TPx)

\begin{tabular}{|c|c|c|c|c|c|}
\hline EH domain-containing 2 & 37.82 & 10.29 & 76.64 & 11.07 & 0.04 \\
\hline Peroxiredoxin 1 & 1.81 & 0.32 & 2.13 & 0.21 & 0.44 \\
\hline Peroxiredoxin 2 & 1.30 & 0.13 & 1.21 & 0.13 & 0.64 \\
\hline Peroxiredoxin 3 & 4.18 & 0.82 & 5.19 & 1.18 & 0.51 \\
\hline Peroxiredoxin 4 & 10.55 & 2.97 & 13.29 & 1.74 & 0.46 \\
\hline Peroxiredoxin 5 & 2.14 & 0.30 & 1.92 & 0.38 & 0.70 \\
\hline Peroxiredoxin 6 & 2.38 & 0.39 & 2.00 & 0.29 & 0.47 \\
\hline \multicolumn{6}{|c|}{ Antioxidants - glutathione peroxidases (GPx) } \\
\hline Glutathione peroxidase 1 & 3.24 & 0.71 & 3.69 & 0.39 & 0.60 \\
\hline Glutathione peroxidase 2 & 571.09 & 150.38 & 1201.89 & 602.13 & 0.35 \\
\hline Glutathione peroxidase 3 & 26.34 & 7.77 & 36.14 & 7.32 & 0.39 \\
\hline Glutathione peroxidase 4 & 0.72 & 0.28 & 1.07 & 0.08 & $\begin{array}{c}0.28 \\
\text { ntinued) }\end{array}$ \\
\hline
\end{tabular}


TABLE 2 | Continued

\begin{tabular}{|c|c|c|c|c|c|}
\hline Gene name & Control mean & Control SOM & Implant mean & Implant SOM & $p$-Value \\
\hline Glutathione peroxidase 5 & $15,244.16$ & 4,227.83 & $25,865.02$ & $12,424.55$ & 0.45 \\
\hline Glutathione peroxidase 6 & $293,809.24$ & $208,228.14$ & $406,834.19$ & $313,034.87$ & 0.80 \\
\hline Glutathione peroxidase 7 & 57.77 & 10.30 & 51.19 & 12.75 & 0.70 \\
\hline Glutathione S-transferase kappa 1 & 11.65 & 2.82 & 11.14 & 2.65 & 0.90 \\
\hline Glutathione S-transferase pi 1 & 3.53 & 0.20 & 3.09 & 0.71 & 0.57 \\
\hline \multicolumn{6}{|l|}{ Antioxidants - other peroxidases } \\
\hline Adenomatous polyposis coli & 1.20 & 0.30 & 1.64 & 0.30 & 0.34 \\
\hline Catalase & 8.36 & 2.02 & 9.77 & 1.46 & 0.59 \\
\hline Cathepsin B & 0.92 & 0.17 & 1.00 & 0.11 & 0.71 \\
\hline Dual oxidase 1 & $63,887.16$ & $46,458.48$ & $103,022.18$ & $68,166.72$ & 0.72 \\
\hline Eosinophil peroxidase & 531.06 & 183.09 & 682.10 & 85.03 & 0.49 \\
\hline Lactoperoxidase & $2,325.71$ & $1,604.08$ & $521,565.32$ & $366,991.43$ & 0.18 \\
\hline Myeloperoxidase & 279.42 & $\mathrm{x}$ & $95,971.49$ & $8,1071.72$ & $\mathrm{x}$ \\
\hline Prostaglandin-endoperoxide synthase 1 & 76.84 & 15.96 & 103.93 & 19.80 & 0.33 \\
\hline Prostaglandin-endoperoxide synthase 2 & 4.63 & 1.22 & 15.08 & 5.11 & 0.09 \\
\hline Recombination activating gene 2 & 10334.28 & $x$ & $x$ & $x$ & $x$ \\
\hline Serine (or cysteine) peptidase inhibitor, clade B, member $1 \mathrm{~b}$ & 721.21 & 169.42 & 979.14 & 436.54 & 0.60 \\
\hline \multicolumn{6}{|l|}{ Oxygen transporters } \\
\hline Cytoglobin & 21.19 & 8.44 & 35.98 & 11.78 & 0.37 \\
\hline Dynamin 2 & 39.75 & 9.21 & 45.30 & 4.03 & 0.60 \\
\hline Fanconi anemia, complementation group C & 62.37 & 12.39 & 66.50 & 8.71 & 0.79 \\
\hline Hemoglobin alpha, adult chain 2 & 293.67 & 221.16 & 88.18 & 36.69 & 0.39 \\
\hline Intraflagellar transport 172 homolog (Chlamydomonas) & 14.65 & 4.23 & 26.25 & 6.62 & 0.19 \\
\hline Myoglobin & $2,014.18$ & $1,400.79$ & $1,021.15$ & 101.09 & 0.58 \\
\hline Neuroglobin & 147.26 & 24.94 & 128.38 & 34.92 & 0.68 \\
\hline Solute carrier family 38, member 1 & 2.26 & 0.13 & 3.07 & 0.72 & 0.31 \\
\hline Solute carrier family 38 , member 5 & 99.09 & 14.70 & 82.06 & 18.44 & 0.50 \\
\hline Vimentin & 9.04 & 4.64 & 8.84 & 5.53 & 0.98 \\
\hline \multicolumn{6}{|l|}{ Other } \\
\hline $\begin{array}{l}\text { Similar to serine/threonine-protein kinase ATR (Ataxia telangiectasia and Rad3-related } \\
\text { protein) }\end{array}$ & $21,362.89$ & $9,743.84$ & $14,220.24$ & $5,207.04$ & 0.59 \\
\hline Selenoprotein S & 4.82 & 0.67 & 5.62 & 0.93 & 0.51 \\
\hline
\end{tabular}

All relative gene expression from implanted animals compared to no surgery control animals. The bold lines indicate genes that were expressed with statistical significance $p<0.05$. The dashed lines indicate the genes that were near statistical significance $p=0.06-0.09$. Power analysis revealed that a sample size of $9 \pm 1$ animals per group, would obtain statistical significance with genes indicating a $p=0.06-0.09$

the prion protein has been linked to several neurodegenerative diseases including Alzheimer's disease and Parkinson's disease (Wemheuer et al., 2017). Scd1 is a key regulator of lipid metabolism (Ntambi and Miyazaki, 2003; Flowers and Ntambi, 2008; Igal, 2010). The human Scd1 gene is anchored in the membrane of the endoplasmic reticulum and is ubiquitously expressed, with highest levels in brain, liver, heart, and lung (Igal, 2010; Liu et al., 2011). Noxa1 is the gene that encodes and regulates the protein NADPH oxidase (NOX1), which is an enzyme that catalyzes the generation of ROS (Ma et al., 2017). Noxal has been reported to be in the blood vessels, neurons, astrocytes, and microglia and in the hippocampus of the brain (Ago et al., 2005; Brown and Griendling, 2009; Choi et al., 2014; Ma et al., 2017).

\section{Oxidative Stress Histological Markers after Electrode Implantation}

Representative images showing a presence of oxidative stress markers for nucleic acid, lipid, and protein damage around the area of implantation are compared to sham control stained tissue (Figure 3). The qualitative images demonstrate increased levels of oxidative damage around the implant site. The images in Figure 3 were stained for hydroxydeoxygaunosine (8-OHdG), a marker of oxidized nucleic acids (Wu et al., 2004), hydroxynonenal (HNE), a marker of oxidized lipids (Ihara et al., 1999), and NT, a marker of oxidized proteins, respectively (Sun et al., 2002). These images clearly show that the there is an accumulation of oxidative stress markers surrounding the site of intracortical microelectrode implantation.

\section{DISCUSSION}

Oxidative stress has been common link between neurological injuries and neurodegenerative disorders (Cobb and Cole, 2015; Kim et al., 2015). However, the presence of oxidative stress following intracortical microelectrode implantation is not clearly defined. Therefore, it was the goal of this study to investigate the presence of oxidative stress after intracortical microelectrode implantation, through gene expression and histological markers. The results of this study have shown a direct connection of oxidative stress markers to intracortical microelectrode implantation. Gene expression analysis revealed four genes to be significantly different in animals implanted with intracortical microelectrodes compared to no surgery control animals. The genes that were significantly overexpressed in animals receiving surgery each play a different, but important role in the physiology of the brain tissue. However, these precise genes are not directly connected within 

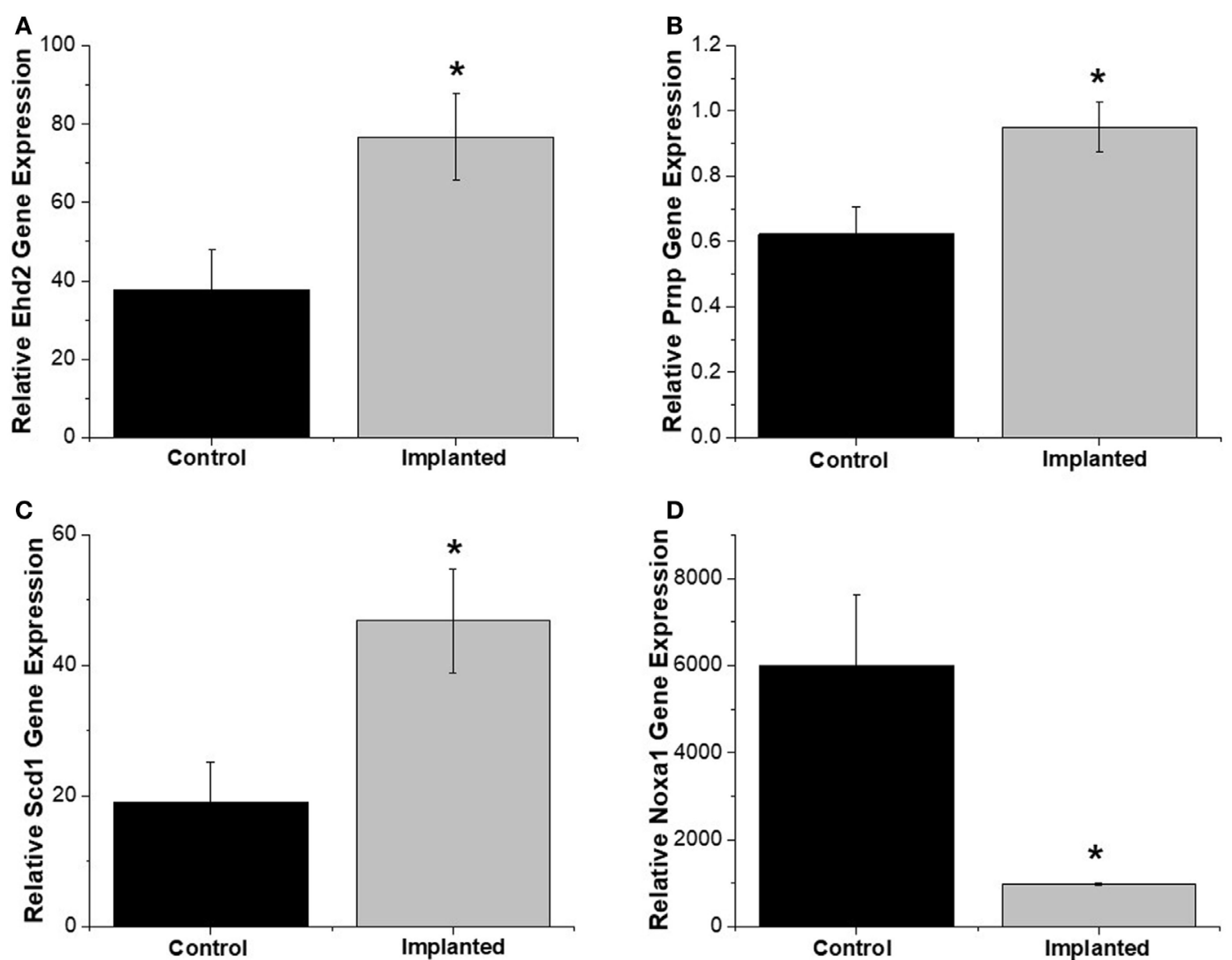

FIGURE 2 | Oxidative stress relative gene expression. Relative gene expression from tissue around implanted animals were quantitatively compared to no surgery control animals. (A) EH domain-containing 2 (Ehd2), (B) Prnp, and (C) Scd1 relative gene expression were significantly higher for implanted animals compared to no surgery controls. (D) Noxa1 relative gene expression was significantly lower in implanted animals compared to no surgery controls. ${ }^{\star}$ denotes $p<0.05$.

one specific pathway. Therefore, the mechanism underlying oxidative stress following intracortical microelectrode implantation is not yet fully understood. However, this study illustrates imperative, novel insight on the oxidative stress response to implanted intracortical microelectrodes.

The significant increase in Ehd2 gene expression in microelectrode implanted animals aligns with the neuroinflammatory response. $\mathrm{EH}$ domains are protein interaction molecules that are associated with the functions of regulating intracellular protein transport/sorting and membrane trafficking, as well as with endocytosis (Carbone et al., 1997; Salcini et al., 1997; Mayer, 1999). The function of Ehd 2 in central nervous system diseases is still incomplete. Ke et al. (2014) investigated the Ehd2 expression in adult rats after intracerebral hemorrhage (a subtype of stroke) and found Ehd2 was upregulated in the perihematomal caudate. Furthermore, Ke et al. (2014) found that Ehd2 was co-localized with apoptotic neurons and activated microglia after intracerebral stroke. A hallmark of the neuroinflammatory response observed after intracortical microelectrode implantation includes activated microglia and a neuronal dieback around the microelectrode interface (Polikov et al., 2005; Jorfi et al., 2014). The role of activated microglia in the neuroinflammatory response is to phagocytose the foreign body (i.e., microelectrode). Thus, the increased expression of Ehd2 was consistent with the validated and understood neuroinflammatory response to implanted microelectrodes.

In adults, the neurons in the brain and spinal cord highly express prion proteins, while glial cells (i.e., astrocytes, microglia, and oligodendrocytes) in the central nervous system and some peripheral nervous system cells (i.e., axons and Schwann cells) express prion proteins at lower levels (Moser et al., 1995; Ford et al., 2002; Westergard et al., 2007; Ding et al., 2013). The prion protein has been shown to be involved in cell death and survival, oxidative stress, immunomodulation, differentiation, metal ion trafficking, cell adhesion, and transmembrane signaling (Aguzzi et al., 2008; Linden et al., 2008). Several neurodegenerative pathologies have been associated with the misfolding of prion proteins, including Alzheimer's disease and Parkinson's disease (Wemheuer et al., 2017).

Alternatively, there has also been evidence suggesting that prion proteins may protect cells from oxidative stress (Milhavet and Lehmann, 2002; Westergard et al., 2007). For example, cell culture studies utilizing neurons from Prnp $^{-1-}$ mice were more susceptible to oxidative stress compared to neurons cultured from wild-type (WT) mice (Brown et al., 1997, 2002). Furthermore, brain tissue from the Prnp ${ }^{-/-}$mice had higher levels of protein oxidation and lipid peroxidation compared to WT mice of the same genetic background (Wong et al., 2001). Accordingly, it is 


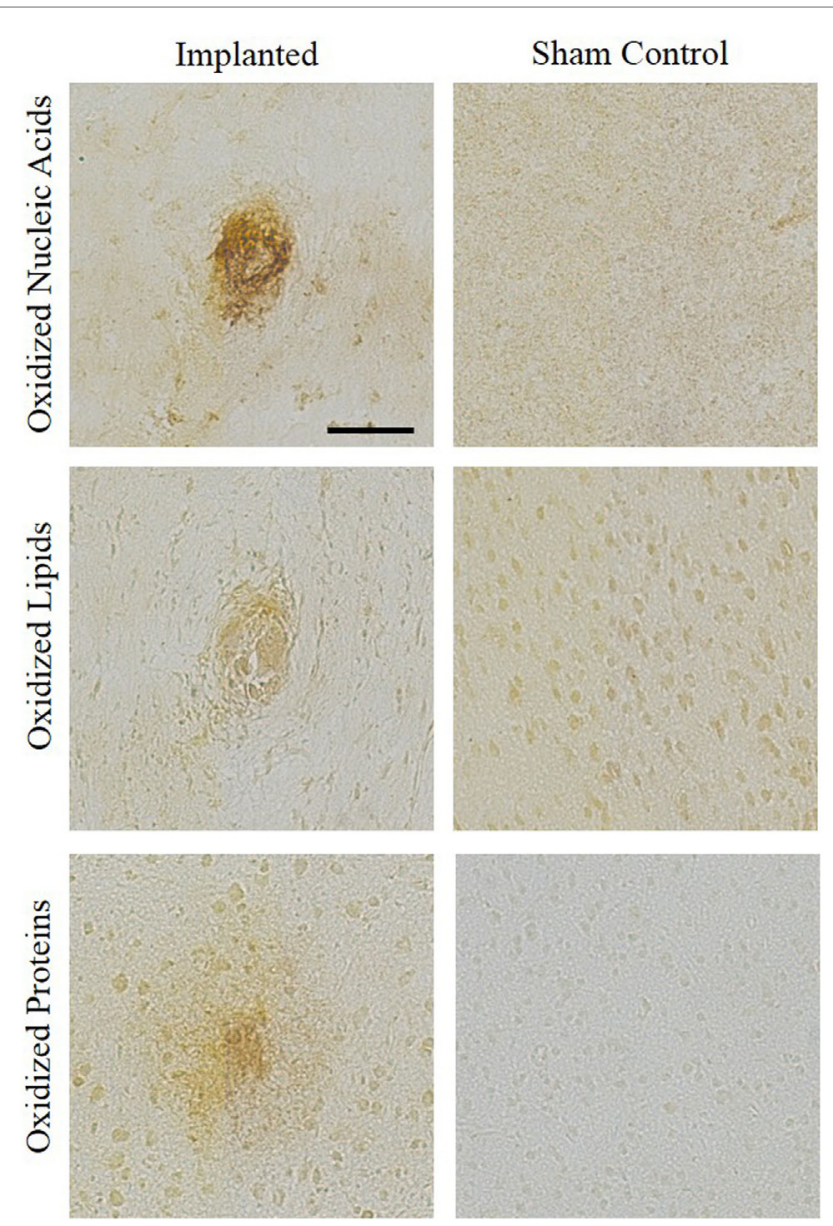

FIGURE 3 | Oxidative stress histological markers. An accumulation of oxidative stress markers around the implant site were shown through staining for hydroxydeoxygaunosine (oxidized nucleic acids), hydroxynonenal (oxidized lipids), and nitrotyrosine (oxidized proteins). No surgery sham controls were stained for comparison.

feasible to hypothesize that the increase in prion protein gene expression observed here is in response to the oxidative stress, and the prion protein gene expression is playing a neuroprotective role.

Chronic blood-brain barrier breach has been shown to correlate with increased neuroinflammation and a reduction in intracortical microelectrode performance (Kozai et al., 2010, 2015; Saxena et al., 2013). The significant differences of Scd1 and Noxal gene expression, both genes typically found in the systemic and cerebral vasculature, lead us to hypothesize the breaching of the blood-brain barrier after microelectrode implantation could be an initiator of the observed increase in oxidative stress. Scd1 catalyzes the synthesis of monounsaturated fatty acids, palmitoleate, and oleate, from saturated fatty acids, palmitate, and stearate, respectively (Ntambi and Miyazaki, 2003; Flowers and Ntambi, 2008; Igal, 2010; Ralston et al., 2016). The regulation of Scd1 expression has been shown to effect the inflammatory response in various cell and tissue types, including adipocyte and macrophage inflammation (Liu et al., 2011). Uryu et al. (2003) found that when inflammation induced by $\beta$-amyloid peptide activation of macrophage occurred, Scd1 gene expression was significantly upregulated, as well as, a set of pro-inflammatory genes. In a later clinical study by Astarita et al. (2011), it was found that the gene expression of Scd1 was significantly elevated in patients with Alzhemier's disease, thus connecting the presence of Scd1 in a diseased brain.

Nox enzymes are transmembrane carriers that reduce oxygen to superoxide anion by transporting electrons from cytosolic NADPH in tissues throughout the body (Ma et al., 2017). Specifically, Nox1 has been found in various areas around the brain, including the cerebral cortex, hippocampus, cerebellum, substantia nigra, striatum, hypothalamus, and cerebral vessels (Hernandes and Britto, 2012; Ma et al., 2017). Several Nox enzymes have been linked to neurodegenerative disorders and injuries. Relevant to this study, Nox1 has been studied in stroke, Parkinson's disease and ALS disease models (Marden et al., 2007; Kahles et al., 2010; Cristóvão et al., 2012). Interestingly, many TBI studies have noted Nox 2 activation following cortical injury as early as $1 \mathrm{~h}$ and up to 28 days post-TBI (Zhang et al., 2012; Cooney et al., 2013; Lu et al., 2014). However, studies evaluating traumatic brain injury due to cortical impact have not examined the activation of Noxlenzymes. Nox2 expression is highly associated with activated microglia ROS production (Brown and Griendling, 2009; Hernandes and Britto, 2012). Other Nox isoforms have been reported to be elevated in the cortex after TBI, including Nox3 and Nox4. Nox3 was also shown to be present in both injured and uninjured neurons (Cooney et al., 2013). As far as we know, this study is the first to investigate the gene expression of Noxal after intracortical microelectrode implantation, or any neurological injury for that matter.

In order to verify the gene expression results, histological staining of oxidative stress markers was performed on the adjacent tissue from the same animal. Previous research has shown increased levels of the oxidative stress markers NT, HNE, and 8-OHdG in neural diseases and disorders. For example, Kuhn et al. (2004) showed that elevated levels of NT correlated to neuronal toxicity leading to the death of dopaminergic neurons. Additionally, Kruman et al. showed that elevated HNE levels led to neuronal apoptosis; while Gmitterová et al. (2009) showed that Parkinson's patients had elevated levels of $8-\mathrm{OHdG}$ in the cerebrospinal fluid. Therefore, the positive histological staining for modified lipids, nucleic acids, and proteins adjacent to the site of intracortical microelectrode implantation indicates that there is a direct correlation between oxidative stress and intracortical microelectrode implantation. While previous studies have shown the link between neurodegenerative disease and oxidative stress (Chen et al., 2012), the current study links intracortical microelectrode implantation with the presence of both histological markers of oxidative stress and changes in gene regulation characteristic of increased oxidative stress.

Oxidative stress plays a role in the inflammatory response, recording quality and failure of the electrodes. Although antioxidants have shown some potential to mitigate this response, they target various pathways and some quench ROS entirely (Potter et al., 2013, 2014; Potter-Baker et al., 2015; Nguyen et al., 2016). We do not want to inhibit all of these pathways and eliminate 
all ROS production, as that will encumber wound healing and normal physiological processes (Popa-Wagner et al., 2013). Here we have identified four genes of interest that can be targeted for therapies. Therefore, when developing new therapeutic treatment strategies to mitigate the oxidative stress and inflammation around implanted microelectrodes, we envision the utilization of successful strategies accomplished by the cancer research community with targeted gene therapy. RNA interference (RNAi) targeted gene therapy has been employed in novel cancer treatments (ex HER2+) (Gavrilov and Saltzman, 2012; Mansoori et al., 2014; Ahmed et al., 2015). We further envision the utilization of RNAi mechanisms, as well as gene knock out models, in order to validate the role of specific genes with oxidative stress following intracortical microelectrode implantation. Following which, RNAi-based drugs can be used as a therapy to reduce oxidative stress around implanted probes.

\section{CONCLUSION}

Together, gene expression and histological staining demonstrated oxidative damage at the intracortical microelectrode/ tissue interface at 4 weeks postimplantation. The increased gene expression of Ehd2, Prnp, and Scd1 along with the positive staining for oxidized proteins, lipids, and nucleic acids revealed an increase in oxidative stress around the implant site compared to the no surgery control animals. This study shows the first direct evidence of oxidative stress following microelectrode implantation and lays the foundation for more detailed mechanistic studies to come. Through the quantitative measurement of these and other genes associated with oxidative damage, at all stages of neuroinflammation and neurodegeneration following intracortical microelectrode implantation, future studies can identify therapeutic targets to mitigate deleterious protein, lipid, and nucleic acid modifications due to oxidative stress pathways associated with microelectrode implantation, including the use of small interfering RNA-mediated gene silencing for specific genes identified in the current study.

\section{ETHICS STATEMENT}

All animal procedures were approved by the Institutional Animal Care and Use Committee (IACUC) at the Louis Stokes Cleveland Department of Veterans Affairs Medical Center.

\section{REFERENCES}

Abbott, N. J., Rönnbäck, L., and Hansson, E. (2006). Astrocyte-endothelial interactions at the blood-brain barrier. Nat. Rev. Neurosci. 7, 41-53. doi:10.1038/ nrn1824

Ago, T., Kitazono, T., Kuroda, J., Kumai, Y., Kamouchi, M., Ooboshi, H., et al. (2005). NAD (P) H oxidases in rat basilar arterial endothelial cells. Stroke 36, 1040-1046. doi:10.1161/01.STR.0000163111.05825.0b

Aguzzi, A., Baumann, F., and Bremer, J. (2008). The prion's elusive reason for being. Annu. Rev. Neurosci. 31, 439-477. doi:10.1146/annurev.neuro.31.060407. 125620

Ahmed, S., Sami, A., and Xiang, J. (2015). HER2-directed therapy: current treatment options for HER2-positive breast cancer. Breast Cancer 22, 101-116. doi:10.1007/s12282-015-0587-x

\section{AUTHOR CONTRIBUTIONS}

EE and JC contributed substantially to the conception or design of the work, analysis, and interpretation of data for the work, drafting, and revising the manuscript for important intellectual content, approved the final version to be published, and agreed to be accountable for all aspects of the work. GR and JH performed the histology experiments and drafted corresponding sections of the manuscript. CS, SM, JR, KC, and HF helped with the acquisition of gene expression data and initial drafts of the manuscript. All authors (EE, GR, JH, CS, SM, JR, KC, HF, and JC) approved the final version to be published and agreed to be accountable for all aspects of the work.

\section{ACKNOWLEDGMENTS}

The authors acknowledge Dr. Xiongwei Zhu and Sandra Siedlak from the Pathology department at Case Western Reserve University for training and providing supplies for the histological protocols used here. The authors thank Drs. Patrick Leahy and Martina Veigl and Mr. Vai Pathak for guidance and assistance with the LCM and RT-PCR. The authors thank Erika Woodrum of the Cleveland Functional Electrical Stimulation (FES) Center for exceptional artistry of Figure 1.

\section{FUNDING}

This study was supported by United States (US) Department of Veterans Affairs Rehabilitation Research and Development Service Merit Review Award \#B1495-R (Capadona), Presidential Early Career Award for Scientist and Engineers (PECASE, Capadona), and Career Development Award 1 \#11800342 (CDA1, Ereifej) from the United States (US) Department of Veterans Affairs Rehabilitation Research and Development Service. The contents do not represent the views of the U.S. Department of Veterans Affairs or the United States Government. This publication was also supported by the Clinical and Translational Science Collaborative of Cleveland, UL1TR000439, from the National Center for Advancing Translational Sciences (NCATS) component of the National Institutes of Health and NIH roadmap for Medical Research. Its contents are solely the responsibility of the authors and do not necessarily represent the official views of the NIH.

Ajiboye, A. B., Willett, F. R., Young, D. R., Memberg, W. D., Murphy, B. A., Miller, J. P., et al. (2017). Restoration of reaching and grasping movements through brain-controlled muscle stimulation in a person with tetraplegia: a proof-of-concept demonstration. Lancet 389, 1821-1830. doi:10.1016/ S0140-6736(17)30601-3

Astarita, G., Jung, K.-M., Vasilevko, V., Dipatrizio, N. V., Martin, S. K., Cribbs, D. H., et al. (2011). Elevated stearoyl-CoA desaturase in brains of patients with Alzheimer's disease. PLOS ONE 6:e24777. doi:10.1371/journal.pone. 0024777

Brown, D. I., and Griendling, K. K. (2009). Nox proteins in signal transduction. Free Radic. Biol. Med. 47, 1239-1253. doi:10.1016/j.freeradbiomed.2009.07.023

Brown, D. R., Nicholas, R. S. J., and Canevari, L. (2002). Lack of prion protein expression results in a neuronal phenotype sensitive to stress. J. Neurosci. Res. 67, 211-224. doi:10.1002/jnr.10118 
Brown, D. R., Schulz-Schaeffer, W. J., Schmidt, B., and Kretzschmar, H. A. (1997). Prion protein-deficient cells show altered response to oxidative stress due to decreased SOD-1 activity. Exp. Neurol. 146, 104-112. doi:10.1006/ exnr.1997.6505

Carbone, R., Fré, S., Iannolo, G., Belleudi, F., Mancini, P., Pelicci, P. G., et al. (1997). eps15 and eps15R are essential components of the endocytic pathway. Cancer Res. 57, 5498-5504.

Chen, X., Guo, C., and Kong, J. (2012). Oxidative stress in neurodegenerative diseases. Neural Regen. Res. 7, 376-385. doi:10.3969/j.issn.1673-5374.2012.05.009

Chestek, C. A., Gilja, V., Nuyujukian, P., Foster, J. D., Fan, J. M., Kaufman, M. T., et al. (2011). Long-term stability of neural prosthetic control signals from silicon cortical arrays in rhesus macaque motor cortex. J. Neural Eng. 8, 045005. doi:10.1088/1741-2560/8/4/045005

Choi, D.-H., Lee, K.-H., Kim, J.-H., Seo, J.-H., Kim, H. Y., Shin, C. Y., et al. (2014). NADPH oxidase 1, a novel molecular source of ROS in hippocampal neuronal death in vascular dementia. Antioxid. Redox Signal. 21, 533-550. doi:10.1089/ ars.2012.5129

Cobb, C. A., and Cole, M. P. (2015). Oxidative and nitrative stress in neurodegeneration. Neurobiol. Dis. 84, 4-21. doi:10.1016/j.nbd.2015.04.020

Cooney, S. J., Bermudez-Sabogal, S. L., and Byrnes, K. R. (2013). Cellular and temporal expression of NADPH oxidase (NOX) isotypes after brain injury. J. Neuroinflammation 10, 917. doi:10.1186/1742-2094-10-155

Cristóvão, A. C., Guhathakurta, S., Bok, E., Je, G., Yoo, S. D., Choi, D.-H., et al. (2012). NADPH oxidase 1 mediates $\alpha$-synucleinopathy in Parkinson's disease. J. Neurosci. 32, 14465-14477. doi:10.1523/JNEUROSCI.2246-12.2012

Dawson, V., and Dawson, T. (1996). Free radicals and neuronal cell death. Cell Death Differ. 3, 71-78.

Ding, T., Zhou, X., Kouadir, M., Shi, F., Yang, Y., Liu, J., et al. (2013). Cellular prion protein participates in the regulation of inflammatory response and apoptosis in BV2 microglia during infection with Mycobacterium bovis. J. Mol. Neurosci. 51, 118-126. doi:10.1007/s12031-013-9962-2

Emerit, J., Edeas, M., and Bricaire, F. (2004). Neurodegenerative diseases and oxidative stress. Biomed. Pharmacother. 58, 39-46. doi:10.1016/j.biopha.2003.11.004

Ereifej, E. S., Smith, C. S., Meade, S. M., Chen, K., Feng, H., and Capadona, J. R. (2017). The neuroinflammatory response to nanopatterning parallel grooves into the surface structure of intracortical microelectrodes. Adv. Funct. Mater. doi:10.1002/adfm.201704420

Flowers, M. T., and Ntambi, J. M. (2008). Role of stearoyl-coenzyme A desaturase in regulating lipid metabolism. Curr. Opin. Lipidol. 19, 248. doi:10.1097/ MOL.0b013e3282f9b54d

Floyd, R. A., and Carney, J. M. (1992). Free radical damage to protein and DNA: mechanisms involved and relevant observations on brain undergoing oxidative stress. Ann. Neurol. 32 Suppl, S22-S27.

Ford, M., Burton, L., Morris, R., and Hall, S. (2002). Selective expression of prion protein in peripheral tissues of the adult mouse. Neuroscience 113, 177-192. doi:10.1016/S0306-4522(02)00155-0

Gallego, D., Rojas, M., and Orozco, C. (2011). "Free radicals, neuronal death and neuroprotection," in Neurodegenerative Diseases-Processes, Prevention, Protection and Monitoring. doi:10.5772/30589

Gavrilov, K., and Saltzman, W. M. (2012). Therapeutic siRNA: principles, challenges, and strategies. Yale J. Biol. Med. 85, 187.

Gilja, V., Pandarinath, C., Blabe, C. H., Nuyujukian, P., Simeral, J. D., Sarma, A. A., et al. (2015). Clinical translation of a high-performance neural prosthesis. Nat. Med. 21, 1142-1145. doi:10.1038/nm.3953

Gmitterová, K., Heinemann, U., Gawinecka, J., Varges, D., Ciesielczyk, B., Valkovic, P., et al. (2009). 8-OHdG in cerebrospinal fluid as a marker of oxidative stress in various neurodegenerative diseases. Neurodegener. Dis 6, 263-269. doi:10.1159/000237221

Goss-Varley, M., Dona, K. R., Mcmahon, J. A., Shoffstall, A. J., Ereifej, E. S., Lindner, S. C., et al. (2017). Microelectrode implantation in motor cortex causes fine motor deficit: Implications on potential considerations to brain computer interfacing and human augmentation. Sci. Rep. 7, 15254. doi:10.1038/ s41598-017-15623-y

Grundfest, H., and Campbell, B. (1942). Origin, conduction and termination of impulses in the dorsal spino-cerebellar tract of cats. J. Neurophysiol. 5, 275-294. doi:10.1152/jn.1942.5.4.275

Grundfest, H., Sengstaken, R. W., Oettinger, W. H., and Gurry, R. (1950). Stainless steel micro-needle electrodes made by electrolytic pointing. Rev. Sci. Instrum. 21, 360-361. doi:10.1063/1.1745583
Hernandes, M. S., and Britto, L. R. G. (2012). NADPH oxidase and neurodegeneration. Curr. Neuropharmacol. 10, 321-327. doi:10.2174/157015912804499483

Igal, R. A. (2010). Stearoyl-CoA desaturase-1: a novel key player in the mechanisms of cell proliferation, programmed cell death and transformation to cancer. Carcinogenesis 31, 1509-1515. doi:10.1093/carcin/bgq131

Ihara, Y., Toyokuni, S., Uchida, K., Odaka, H., Tanaka, T., Ikeda, H., et al. (1999). Hyperglycemia causes oxidative stress in pancreatic beta-cells of GK rats, a model of type 2 diabetes. Diabetes 48, 927-932. doi:10.2337/diabetes.48.4.927

Jorfi, M., Skousen, J. L., Weder, C., and Capadona, J. R. (2014). Progress towards biocompatible intracortical microelectrodes for neural interfacing applications. J. Neural Eng. 12, 011001. doi:10.1088/1741-2560/12/1/011001

Kahles, T., Kohnen, A., Heumueller, S., Rappert, A., Bechmann, I., Liebner, S., et al. (2010). NADPH oxidase Nox1 contributes to ischemic injury in experimental stroke in mice. Neurobiol. Dis. 40, 185-192. doi:10.1016/j.nbd.2010.05.023

Karumbaiah, L., Saxena, T., Carlson, D., Patil, K., Patkar, R., Gaupp, E. A., et al. (2013). Relationship between intracortical electrode design and chronic recording function. Biomaterials 34, 8061-8074. doi:10.1016/j.biomaterials. 2013.07.016

Ke, K., Rui, Y., Li, L., Zheng, H., Xu, W., Tan, X., et al. (2014). Upregulation of EHD2 after intracerebral hemorrhage in adult rats. J. Mol. Neurosci. 54, 171-180. doi:10.1007/s12031-014-0271-1

Kettenmann, H., Hanisch, U.-K., Noda, M., and Verkhratsky, A. (2011). Physiology of microglia. Physiol. Rev. 91, 461-553. doi:10.1152/physrev.00011.2010

Kim, G. H., Kim, J. E., Rhie, S. J., and Yoon, S. (2015). The role of oxidative stress in neurodegenerative diseases. Exp. Neurobiol. 24, 325-340. doi:10.5607/ en.2015.24.4.325

Kozai, T., Marzullo, T., Hooi, F., Langhals, N., Majewska, A., Brown, E., et al. (2010). Reduction of neurovascular damage resulting from microelectrode insertion into the cerebral cortex using in vivo two-photon mapping. J. Neural Eng. 7, 046011. doi:10.1088/1741-2560/7/4/046011

Kozai, T. D. Y., Jaquins-Gerstl, A. S., Vazquez, A. L., Michael, A. C., and Cui, X. T. (2015). Brain tissue responses to neural implants impact signal sensitivity and intervention strategies. ACS Chem. Neurosci. 6, 48-67. doi:10.1021/cn500256e

Kuhn, D. M., Sakowski, S. A., Sadidi, M., and Geddes, T. J. (2004). Nitrotyrosine as a marker for peroxynitrite-induced neurotoxicity: the beginning or the end of the end of dopamine neurons? J. Neurochem. 89, 529-536. doi:10.1111/j.1471-4159.2004.02346.x

Lee, H.-P., Pancholi, N., Esposito, L., Previll, L. A., Wang, X., Zhu, X., et al. (2012). Early induction of oxidative stress in mouse model of Alzheimer disease with reduced mitochondrial superoxide dismutase activity. PLoS ONE 7:e28033. doi:10.1371/journal.pone.0028033

Lin, M. T., and Beal, M. F. (2006). Mitochondrial dysfunction and oxidative stress in neurodegenerative diseases. Nature 443, 787. doi:10.1038/nature05292

Linden, R., Martins, V. R., Prado, M. A., Cammarota, M., Izquierdo, I., and Brentani, R. R. (2008). Physiology of the prion protein. Physiol. Rev. 88, 673-728. doi:10.1152/physrev.00007.2007

Liu, X., Strable, M. S., and Ntambi, J. M. (2011). Stearoyl CoA desaturase 1: role in cellular inflammation and stress. Adv. Nutr. 2, 15-22. doi:10.3945/an.110.000125

Livak, K. J., and Schmittgen, T. D. (2001). Analysis of relative gene expression data using real-time quantitative PCR and the 2- $\Delta \Delta$ CT method. Methods 25, 402-408. doi:10.1006/meth.2001.1262

Lu, X.-Y., Wang, H.-D., Xu, J.-G., Ding, K., and Li, T. (2014). NADPH oxidase inhibition improves neurological outcome in experimental traumatic brain injury. Neurochem. Int. 69, 14-19. doi:10.1016/j.neuint.2014.02.006

Ma, M. W., Wang, J., Zhang, Q., Wang, R., Dhandapani, K. M., Vadlamudi, R. K., et al. (2017). NADPH oxidase in brain injury and neurodegenerative disorders. Mol. Neurodegener. 12, 7. doi:10.1186/s13024-017-0150-7

Mansoori, B., Shotorbani, S. S., and Baradaran, B. (2014). RNA interference and its role in cancer therapy. Adv. Pharm. Bull. 4, 313. doi:10.5681/apb.2014.046

Marden, J. J., Harraz, M. M., Williams, A. J., Nelson, K., Luo, M., Paulson, H., et al. (2007). Redox modifier genes in amyotrophic lateral sclerosis in mice. J. Clin. Invest. 117, 2913. doi:10.1172/JCI31265

Mayer, B. J. (1999). Endocytosis: EH domains lend a hand. Curr. Biol. 9, R70-R73. doi:10.1016/S0960-9822(99)80014-1

McConnell, G. C., Rees, H. D., Levey, A. I., Gutekunst, C. A., Gross, R. E., and Bellamkonda, R. V. (2009). Implanted neural electrodes cause chronic, local inflammation that is correlated with local neurodegeneration. J. Neural Eng. 6, 056003. doi:10.1088/1741-2560/6/5/056003 
McConnell, G.C. (2008). Chronic Inflammation Surrounding Intra-cortical Electrodes is Correlated with a Local Neurodegenerative State. Ph.D., Georgia Institute of Technology.

Milhavet, O., and Lehmann, S. (2002). Oxidative stress and the prion protein in transmissible spongiform encephalopathies. Brain Res. Rev. 38, 328-339. doi:10.1016/S0165-0173(01)00150-3

Moser, M., Colello, R. J., Pott, U., and Oesch, B. (1995). Developmental expression of the prion protein gene in glial cells. Neuron 14, 509-517. doi:10.1016/0896-6273(95)90307-0

Nguyen, J. K., Jorfi, M., Buchanan, K. L., Park, D. J., Foster, E. J., Tyler, D. J., et al. (2016). Influence of resveratrol release on the tissue response to mechanically adaptive cortical implants. Acta Biomater. 29, 81-93. doi:10.1016/j. actbio.2015.11.001

Nguyen, J. K., Park, D. J., Skousen, J.L., Hess-Dunning, A., Tyler, D. J., Rowan, S. J., et al. (2014). Mechanically-compliant intracortical implants reduce the neuroinflammatory response. J. Neural Eng. 11, 056014. doi:10.1088/1741-2560/11/5/056014

Ntambi, J. M., and Miyazaki, M. (2003). Recent insights into stearoyl-CoA desaturase-1. Curr. Opin. Lipidol. 14, 255-261. doi:10.1097/00041433-20030600000005

Pohl, U., Smith, J. S., Tachibana, I., Ueki, K., Lee, H. K., Ramaswamy, S., et al. (2000). EHD2, EHD3, and EHD4 encode novel members of a highly conserved family of EH domain-containing proteins. Genomics 63, 255-262. doi:10.1006/geno.1999.6087

Polikov, V. S., Tresco, P. A., and Reichert, W. M. (2005). Response of brain tissue to chronically implanted neural electrodes. J. Neurosci. Methods 148, 1-18. doi:10.1016/j.jneumeth.2005.08.015

Popa-Wagner, A., Mitran, S., Sivanesan, S., Chang, E., and Buga, A.-M. (2013). ROS and brain diseases: the good, the bad, and the ugly. Oxid. Med. Cell. Longev. 2013, 14. doi:10.1155/2013/963520

Potter, K. A., Buck, A. C., Self, W. K., Callanan, M. E., Sunil, S., and Capadona, J. R. (2013). The effect of resveratrol on neurodegeneration and blood brain barrier stability surrounding intracortical microelectrodes. Biomaterials 34 , 7001-7015. doi:10.1016/j.biomaterials.2013.05.035

Potter, K. A., Buck, A. C., Self, W. K., and Capadona, J. R. (2012a). Stab injury and device implantation within the brain results in inversely multiphasic neuroinflammatory and neurodegenerative responses. J. Neural Eng. 9, 046020. doi:10.1088/1741-2560/9/4/046020

Potter, K. A., Simon, J. S., Velagapudi, B., and Capadona, J. R. (2012b). Reduction of autofluorescence at the microelectrode-cortical tissue interface improves antibody detection. J. Neurosci. Methods 203, 96-105. doi:10.1016/j. jneumeth.2011.09.024

Potter, K. A., Jorfi, M., Householder, K. T., Foster, E. J., Weder, C., and Capadona, J. R. (2014). Curcumin-releasing mechanically-adaptive intracortical implants improve the proximal neuronal density and blood-brain barrier stability. Acta Biomater. 10, 2209-2222. doi:10.1016/j.actbio.2014.01.018

Potter-Baker, K. A., and Capadona, J. R. (2015). Reducing the "stress": antioxidative therapeutic and material approaches may prevent intracortical microelectrode failure. ACS Macro Lett. 4, 275-279. doi:10.1021/mz500743a

Potter-Baker, K. A., Nguyen, J. K., Kovach, K. M., Gitomer, M. M., Srail, T. W., Stewart, W. G., et al. (2014). Development of superoxide dismutase mimetic surfaces to reduce accumulation of reactive oxygen species surrounding intracortical microelectrodes. J. Mater. Chem. B 2, 2248-2258. doi:10.1039/ C4TB00125G

Potter-Baker, K. A., Stewart, W. G., Tomaszewski, W. H., Wong, C. T., Meador, W. D., Ziats, N. P., et al. (2015). Implications of chronic daily anti-oxidant administration on the inflammatory response to intracortical microelectrodes. J. Neural Eng. 12, 046002. doi:10.1088/1741-2560/12/4/046002

Prasad, A., Xue, Q.-S., Dieme, R., Sankar, V., Mayrand, R., Nishida, T., et al. (2014). Abiotic-biotic characterization of $\mathrm{Pt} / \mathrm{Ir}$ microelectrode arrays in chronic implants. Front. Neuroeng. 7:2. doi:10.3389/fneng.2014.00002

Prasad, A., Xue, Q. S., Sankar, V., Nishida, T., Shaw, G., Streit, W. J., et al. (2012). Comprehensive characterization and failure modes of tungsten microwire arrays in chronic neural implants. J. Neural Eng. 9, 056015. doi:10.1088/1741-2560/9/5/056015

Ralston, J. C., Metherel, A. H., Stark, K. D., and Mutch, D. M. (2016). SCD1 mediates the influence of exogenous saturated and monounsaturated fatty acids in adipocytes: effects on cellular stress, inflammatory markers and fatty acid elongation. J. Nutr. Biochem. 27, 241-248. doi:10.1016/j.jnutbio.2015.09.011
Ravikumar, M., Sunil, S., Black, J., Barkauskas, D., Haung, A. Y., Miller, R. H., et al. (2014). The roles of blood-derived macrophages and resident microglia in the neuroinflammatory response to implanted intracortical microelectrodes. Biomaterials 35, 8049-8064. doi:10.1016/j.biomaterials.2014. 05.084

Renshaw, B., Forbes, A., and Morison, B. (1940). Activity of isocortex and hippocampus: electrical studies with micro-electrodes. J. Neurophysiol. 3, 74-105. doi:10.1152/jn.1940.3.1.74

Salcini, A. E., Confalonieri, S., Doria, M., Santolini, E., Tassi, E., Minenkova, O., et al. (1997). Binding specificity and in vivo targets of the EH domain, a novel protein-protein interaction module. Genes Dev. 11, 2239-2249. doi:10.1101/ gad.11.17.2239

Saxena, T., Karumbaiah, L., Gaupp, E. A., Patkar, R., Patil, K., Betancur, M., et al. (2013). The impact of chronic blood-brain barrier breach on intracortical electrode function. Biomaterials 34, 4703-4713. doi:10.1016/j. biomaterials.2013.03.007

Schmitt, G., Schultze, J.-W., Buß, G., Lüth, H., and Schöning, M. J. (1999). Passivation and corrosion of microelectrode arrays. Electrochim. Acta 44, 3865-3883. doi:10.1016/S0013-4686(99)00094-8

Schmittgen, T. D., and Livak, K. J. (2008). Analyzing real-time PCR data by the comparative CT method. Nat. Protoc. 3, 1101-1108. doi:10.1038/nprot.2008.73

Schroeder, K. E., and Chestek, C. A. (2016). Intracortical brain-machine interfaces advance sensorimotor neuroscience. Front. Neurosci. 10:291. doi:10.3389/ fnins.2016.00291

Smith, M. A., Rottkamp, C. A., Nunomura, A., Raina, A. K., and Perry, G. (2000). Oxidative stress in Alzheimer's disease. Biochim. Biophys. Acta 1502, 139-144. doi:10.1016/S0925-4439(00)00040-5

Streit, W. J., Walter, S. A., and Pennell, N. A. (1999). Reactive microgliosis. Prog. Neurobiol. 57, 563-581. doi:10.1016/S0301-0082(98)00069-0

Sun, Y., Zhang, J., Lu, L., Chen, S. S., Quinn, M. T., and Weber, K. T. (2002). Aldosterone-induced inflammation in the rat heart: role of oxidative stress. Am. J. Pathol. 161, 1773-1781. doi:10.1016/S0002-9440(10)64454-9

Takmakov, P., Ruda, K., Phillips, K. S., Isayeva, I. S., Krauthamer, V., and Welle, C. G. (2015). Rapid evaluation of the durability of cortical neural implants using accelerated aging with reactive oxygen species. J. Neural Eng. 12, 026003. doi:10.1088/1741-2560/12/2/026003

Uryu, S., Tokuhiro, S., and Oda, T. (2003). $\beta$-Amyloid-specific upregulation of stearoyl coenzyme A desaturase-1 in macrophages. Biochem. Biophys. Res. Commun. 303, 302-305. doi:10.1016/S0006-291X(03)00334-6

Wemheuer, W. M., Wrede, A., and Schulz-Schaeffer, W. J. (2017). Types and strains: their essential role in understanding protein aggregation in neurodegenerative diseases. Front. Aging Neurosci. 9:187. doi:10.3389/fnagi.2017.00187

Westergard, L., Christensen, H. M., and Harris, D. A. (2007). The cellular prion protein (PrP C): its physiological function and role in disease. Biochim. Biophys. Acta 1772, 629-644. doi:10.1016/j.bbadis.2007.02.011

Wong, B. S., Liu, T., Li, R., Pan, T., Petersen, R. B., Smith, M. A., et al. (2001). Increased levels of oxidative stress markers detected in the brains of mice devoid of prion protein. J. Neurochem. 76, 565-572. doi:10.1046/j.1471-4159.2001. 00028.x

Wu, L. L., Chiou, C.-C., Chang, P.-Y., and Wu, J. T. (2004). Urinary 8-OHdG: a marker of oxidative stress to DNA and a risk factor for cancer, atherosclerosis and diabetics. Clin. Chim. Acta 339, 1-9. doi:10.1016/j.cccn.2003.09.010

Zhang, Q.-G., Laird, M. D., Han, D., Nguyen, K., Scott, E., Dong, Y., et al. (2012). Critical role of NADPH oxidase in neuronal oxidative damage and microglia activation following traumatic brain injury. PLoS ONE 7:e34504. doi:10.1371/ journal.pone.0034504

Conflict of Interest Statement: The authors declare that the research was conducted in the absence of any commercial or financial relationships that could be construed as a potential conflict of interest.

Copyright @ 2018 Ereifej, Rial, Hermann, Smith, Meade, Rayyan, Chen, Feng and Capadona. This is an open-access article distributed under the terms of the Creative Commons Attribution License (CC BY). The use, distribution or reproduction in other forums is permitted, provided the original author(s) and the copyright owner are credited and that the original publication in this journal is cited, in accordance with accepted academic practice. No use, distribution or reproduction is permitted which does not comply with these terms. 